\title{
Improvement in TNM staging of pulmonary neuroendocrine tumors requires histology and regrouping of tumor size
}

\author{
Maria Cattoni, MD, ${ }^{a}$ Eric Vallières, MD, ${ }^{a}$ Lisa M. Brown, MD, MAS, ${ }^{b}$ Amir A. Sarkeshik, MD, ${ }^{b}$ \\ Stefano Margaritora, MD, ${ }^{\mathrm{c}}$ Alessandra Siciliani, MD, ${ }^{\mathrm{c}}$ Pier Luigi Filosso, MD, ${ }_{\mathrm{d}}^{\mathrm{d}}$ Francesco Guerrera, MD, ${ }^{\mathrm{d}}$ \\ Andrea Imperatori, MD, ${ }^{\mathrm{e}}$ Nicola Rotolo, MD,${ }^{\mathrm{e}}$ Farhood Farjah, MD, MPH, ${ }^{\mathrm{f}}$ Grace Wandell, MSc, ${ }^{\mathrm{f}}$ \\ Kimberly Costas, MD, ${ }^{\mathrm{g}}$ Catherine Mann, MD, ${ }^{\mathrm{a}}$ Michal Hubka, MD, ${ }^{\mathrm{h}}$ Stephen Kaplan, MD, \\ Alexander S. Farivar, MD, ${ }^{a}$ Ralph W. Aye, MD, ${ }^{a}$ and Brian E. Louie, MD, MHA, MPH ${ }^{\mathrm{a}}$
}

\section{ABSTRACT}

Objective: Neuroendocrine tumors of the lung are currently staged with the 7th edition TNM non-small cell lung cancer staging system. This decision, based on data analysis without data on histology or disease-specific survival, makes its applicability limited. This study proposes a specific staging system for these tumors.

Methods: We retrospectively analyzed 510 consecutive patients (female/male, 313/197; median age, 61 years; interquartile range, 51-70) undergoing lung resection for a primary neuroendocrine tumor between 2000 and 2015 in 8 centers. Multivariable analysis was performed using a Cox proportional hazard model to identify factors associated with disease-specific survival. A new staging system was proposed on the basis of the results of this analysis. Kaplan-Meier disease-specific survival was analyzed by stage using the proposed and the 7th TNM staging system.

Results: Follow-up was completed in 490 of 510 patients at a median of 51 months (interquartile range, 18-99). Histology (G1-typical carcinoid vs G2-atypical carcinoid vs G3-large-cell neuroendocrine carcinoma) and $\mathrm{pT}$ were independently associated with survival, but $\mathrm{pN}$ was not. After regrouping histology and $\mathrm{pT}$, we proposed the following staging system: IA (pT1-2G1), IB (pT3G1, pT1G2), IIA (pT4G1, pT2-3G2, pT1G3), IIB (pT4G2, pT2-3G3), and III (pT4G3). The 5 -year survivals were $97.9 \%, 81.0 \%, 69.1 \%, 51.8 \%$, and $0 \%$, respectively. By using the 7 th TNM, 5-year survivals were $95.0 \%, 92.3 \%, 67.7 \%, 70.9 \%$, and $65.1 \%$ for stage IA, IB, IIA, IIB, and III, respectively.

Conclusions: Incorporating histology and regrouping tumor stage create a unique neuroendocrine tumor staging system that seems to predict survival better than the 7th TNM classification. (J Thorac Cardiovasc Surg 2018;155:405-13)

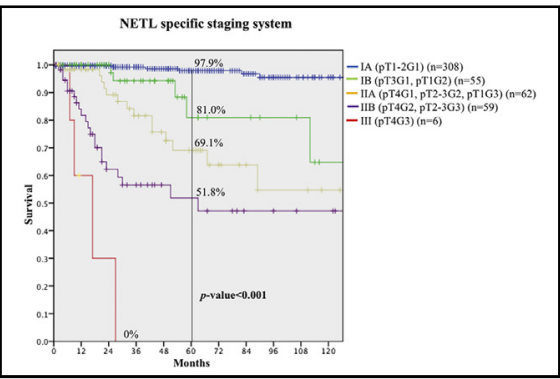

A proposed neuroendocrine tumor staging system separates survival curves between stages.

\section{Central Message}

Incorporating histology and regrouping tumor stages create a pulmonary neuroendocrine tumor staging system that seems to predict disease-specific survival better than the AJCC 7th edition TNM.

\section{Perspective}

NETL are a separate entity from NSCLC, yet they are staged with the 7th edition TNM lung cancer system. This limits the utility of staging these tumors. By incorporating the 2 factors that influence diseasespecific survival, histology, and tumor stage, a unique NETL staging system can be created to predict survival better than the current system.

See Editorial Commentary page 414.

See Editorial page 367.

\footnotetext{
From the ${ }^{\mathrm{a}}$ Division of Thoracic Surgery, Swedish Cancer Institute; ${ }^{\mathrm{f}}$ Division of Cardiothoracic Surgery, University of Washington Medical Center; ${ }^{\mathrm{h}}$ Division of Thoracic Surgery, Virginia Mason Hospital \& Seattle Medical Center, Seattle; ${ }^{g}$ Division of Thoracic Surgery, Providence Regional Medical Center, Everett, Wash; ' Section of General Thoracic Surgery, Department of Surgery, UC Davis Health, Sacramento, Calif; ' ${ }^{\mathrm{C}}$ Unit of Thoracic Surgery, Catholic University of Sacred Heart, Rome; ${ }^{\mathrm{d} D e p a r t m e n t}$ of Thoracic Surgery, San Giovanni Battista Hospital, Torino; and ${ }^{\mathrm{e}}$ Center of Thoracic Surgery, Department of Surgical and Morphological Sciences, University of Insubria, Ospedale di Circolo, Varese, Italy. Read at the 97th Annual Meeting of The American Association for Thoracic Surgery, Boston, Massachusetts, April 29-May 3, 2017.

Received for publication May 4, 2017; revisions received Aug 12, 2017; accepted for publication Aug 25, 2017; available ahead of print Oct 3, 2017.

Address for reprints: Brian E. Louie, MD, MHA, MPH, Division of Thoracic Surgery, 900-1101 Madison St, Seattle, WA 98104 (E-mail: brian.louie@swedish.org). $0022-5223 / \$ 36.00$

Copyright (c) 2017 by The American Association for Thoracic Surgery https://doi.org/10.1016/j.jtcvs.2017.08.102
}

Cancer staging systems are designed to provide a common method of evaluating the extent of disease and to predict survival. For common thoracic cancers such as esophageal cancer or non-small cell lung cancer (NSCLC), there is a disease-specific staging system derived from large datasets and multiple outcome studies that allows a reliable and

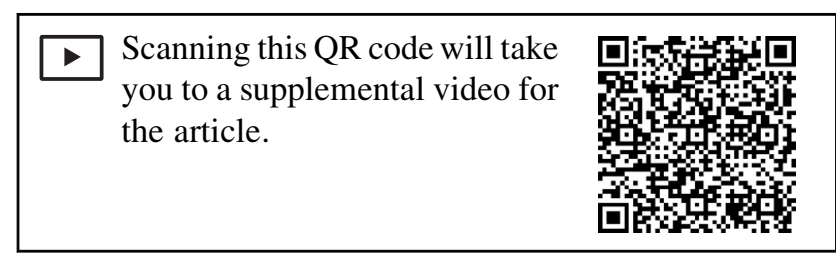




\section{Abbreviations and Acronyms \\ AJCC = American Joint Committee on Cancer \\ $\mathrm{CI}=$ confidence interval \\ ESTS = European Society Thoracic Surgery \\ NETL = neuroendocrine tumors of the lung \\ NSCLC $=$ non-small cell lung cancer}

reproducible prediction of outcomes. For rare tumors, there may not be a disease-specific staging system, and staging may be attempted using a related system. Neuroendocrine tumors of the lung (NETL), with an incidence of 5.25 cases per 100,000 persons in the United States, are an example of a rare tumor without a disease-specific staging system. ${ }^{1}$ These tumors were excluded from the 2003 American Joint Committee on Cancer (AJCC) staging manual, although many physicians were applying the TNM non-small cancer staging descriptors to these tumors.

After an analysis of data from the International Association for the Study of Lung Cancer and the National Cancer Institute Surveillance Epidemiology and End Results, it was determined that application of the NSCLC staging system to pulmonary carcinoid tumors was suitable for predicting outcomes. ${ }^{2}$ However, there are several limitations when applying the NSCLC staging system to NETL. First, NETL are considered a separate entity from NSCLC because of their peculiar morphologic, ultrastructural, immunohistochemical, and molecular characteristics. ${ }^{3}$ Second, there is a spectrum of disease ranging from indolent typical carcinoid or low-grade neuroendocrine tumors to atypical carcinoid or intermediate-grade neuroendocrine tumor and to the high-grade, aggressive subtypes, large-cell neuroendocrine carcinoma, and small-cell neuroendocrine carcinoma. ${ }^{3}$ Survival outcomes using the current system have demonstrated overlaps in survival curves across different staging classes. ${ }^{4}$ This suggests there is a need for improvement in neuroendocrine tumor staging.

With the use of a large, multi-institutional dataset of neuroendocrine tumors, we aim to identify factors associated with disease-specific survival after surgical resection of NETL and propose a disease-specific staging system for these neoplasms.

\footnotetext{
MATERIAL AND METHODS

We retrospectively collected and analyzed the data of consecutive patients undergoing curative resection for primary NETL between 2000 and 2015 in 8 centers. Participating institutions included Swedish Cancer Institute, Seattle, Washington; University of California Davis Health, Sacramento, California; Catholic University of Sacred Heart, Rome, Italy; San Giovanni Battista Hospital, Torino, Italy; University of Insubria, Ospedale di Circolo, Varese, Italy; University of Washington Medical Center, Seattle, Washington; Providence Regional Medical Center, Everett, Washington; and Virginia Mason Hospital and Medical Center, Seattle,
}

Washington. Patients with macroscopic or microscopic tumor infiltration of the resection margins or without these data reported and small cell carcinoma were excluded from the study. The institutional review board at each center approved this study and de-identified data were transmitted between centers. Individual patient consent was waived because of the retrospective nature of the study.

For each patient, we collected the following data: age, gender, smoking habit, Eastern Cooperative Oncology Group performance status, forced expiratory volume in 1 second, previous malignancy, preoperative investigations, tumor location, clinical 7th edition TNM stage, surgical reports, pathologic findings, induction/adjuvant therapy, and follow-up. Standardized definitions for each data point were decided a priori on the basis of previous literature and distributed to each center for use. Tumor location was defined as "central" when tumors were visualized at bronchoscopy or associated with lung atelectasis or obstructive pneumonia and "peripheral" when not visualized at bronchoscopy. 5

Univariable and multivariable analyses were performed to identify factors associated with disease-specific survival. Factors analyzed were age, sex, smoking history, Eastern Cooperative Oncology Group performance status, prior malignancies, presence of symptoms, extent of lung resection (sublobar and bronchial sleeve resections vs greater resections), lymphadenectomy, histologic subtype, pT, tumor location, and nodal status ( $\mathrm{pN})$. pT and $\mathrm{pN}$ were defined according to the 7 th edition TNM staging system for NSCLC. When $\mathrm{pN}$ was not available because no lymph node sampling or dissection was performed during surgery, we used $\mathrm{cN}$ only if no lymph node involvement was reported during the follow-up.

By using the significant variables (age, gender, smoking status, histology, $\mathrm{pT}$, and $\mathrm{pN}$ ) from the univariable analysis, a series of multivariable models were created on the basis of the degree of significance and clinical importance. Both histology and pT were identified as significant variables in each model created regardless of whether age, gender, and smoking status were included. The final multivariable model demonstrates that after adjusting for histology and $\mathrm{pT}, \mathrm{pN}$ is not a significant predictor; however, it was retained because of its clinical importance in all staging systems. The changes in hazard ratio estimates for histology and pT with and without $\mathrm{pN}$ in the model were small and not clinically meaningful. ${ }^{6}$

We used the results of the multivariable analysis to create survival and recurrence tables on the basis of tumor histology and pathologic tumor stage (pT). We designated low-grade neuroendocrine histology (typical carcinoid) as G1, intermediate-grade (atypical carcinoid) as G2, and high-grade (large-cell neuroendocrine carcinoma) as G3. In each tumor grade, we grouped patients by the AJCC 7th edition, lung cancer tumor groupings based on size (in centimeters), and associated descriptors such as atelectasis, proximity to the carina, and multiple nodules. New stage groupings were created by incorporating tumor sizes and the associated descriptors, and histology with similar survival and recurrences.

Once the new staging groups were created, we used the Kaplan-Meier method and the Cox proportional hazards model stratified by center to evaluate the differences in disease-specific survival between the different stages to determine whether the new staging system discriminated as well, worse, or better than the existing TNM classification.

Continuous data were reported as median with interquartile range. Categoric and count data were presented as frequencies and percentages. Disease-specific survival was defined as the time interval in months from the date of surgery to the last follow-up. The univariate and multivariate analyses were completed using the Cox proportional hazards model. Statistical analyses were undertaken using primarily SPSS 24.0 software (IBM Corp, Armonk, NY).

\section{RESULTS}

From 2000 to 2015, 551 patients underwent curative lung surgery for primary NETL in 8 international centers. A total 
TABLE 1. Patients' demographics and clinical characteristics

\begin{tabular}{|c|c|}
\hline Patient characteristics & \\
\hline Median age, y (IQR) & $61(51-70)$ \\
\hline Male, n (\%) & 197 (39) \\
\hline Current/former smoker, n (\%) & $287(57)^{*}$ \\
\hline \multicolumn{2}{|l|}{ ECOG performance status, $\mathrm{n}(\%)$} \\
\hline 0 & $366(72)$ \\
\hline 1 & $122(24)$ \\
\hline$\geq 2$ & $22(4)$ \\
\hline Median $\mathrm{FEV}_{1}, \%$ (IQR) & $87(75-101) \dagger$ \\
\hline Previous malignancy, n (\%) & $89(18) \ddagger$ \\
\hline Symptoms at diagnosis, $\mathrm{n}(\%)$ & $256(51) \S$ \\
\hline
\end{tabular}

of 41 cases (patients with tumor infiltration at the resection margins or without this information reported) were excluded from the study, leaving 510 patients for the analysis. This cohort had a median age of 60 years, was predominantly female with a prior or current history of smoking. Approximately half were symptomatic at presentation, and most had a good performance status (Table 1).

All 510 patients underwent preoperative imaging for clinical staging, including 204 computed tomography scans and 306 computed tomography with fluorodeoxyglucose positron emission tomography scans. Of the 510 patients, 117 underwent additional staging investigations including somatostatin receptor scintigraphy (62), endobronchial ultrasound-guided transbronchial needle aspiration (8), and mediastinoscopy or other surgical biopsy (54). These data were not available in 4 patients. Preoperative biopsy of the main tumor was obtained in 390 patients, including endoscopic biopsy (225), transthoracic biopsy (156), surgical biopsy (5), and others (4). This information was not available in 7 patients.

All patients underwent surgical resection of their NETL. Some $77 \%$ of patients underwent an anatomic resection of a lobe or greater. Only $2 \%$ of patients underwent a bronchial sleeve resection without parenchymal removal. Of the 77 wedge resections, $76 \%$ (59/77) had a typical carcinoid, $12 \%(9 / 77)$ had an atypical carcinoid, and 12\% (9/77) had a large cell neuroendocrine carcinoma. Nodal sampling or lymphadenectomy was completed in $87 \%$ of patients (Table 2).

Final histology revealed a low-grade NETL or typical carcinoid (G1) in 341 of 510 patients $(67 \%)$, an intermediate-grade NETL or atypical carcinoid (G2) in 68 of 510 patients $(13 \%)$, and a high-grade NETL or large-cell neuroendocrine carcinoma (G3) in 101 of 510 patients $(20 \%)$. Pathologic features and 7 th edition TNM staging results are listed in Table 2. The distribution of
TABLE 2. Operative details and pathologic analysis according to the 7th edition TNM

\begin{tabular}{lc}
\hline \multicolumn{2}{c}{ Surgical reports and tumor characteristics } \\
\hline Extension of lung resection, $\mathrm{n}(\%)$ & $19(4)$ \\
Pneumonectomy & $31(6)$ \\
Bilobectomy & $341(67)^{*}$ \\
Lobectomy & $33(6)$ \\
Segmentectomy & $77(15)$ \\
Wedge resection & $9(2)$ \\
Bronchial sleeve resection & $444(87) \dagger$ \\
Lymphadenectomy/sampling, $\mathrm{n}(\%)$ & $2.0(1.4-3.2)$ \\
Median tumor size, cm (IQR) & $329(65) \ddagger$ \\
Peripheral tumor, $\mathrm{n}(\%)$ & \\
pT, $\mathrm{n}(\%)$ & $327(64)$ \\
pT1 & $120(24)$ \\
pT2 & $53(10)$ \\
pT3 & $10(2)$ \\
pT4 & \\
pN, $\mathrm{n}(\%)$ & $412(81)$ \\
pN0 & $62(12)$ \\
pN1 & $36(7)$ \\
pN2-3 & \\
Pathologic stage, $\mathrm{n}(\%)$ & $289(57)$ \\
IA & $71(14)$ \\
IB & $52(10)$ \\
IIA & $40(8)$ \\
IIB & $58(11)$ \\
III &
\end{tabular}

$I Q R$, Interquartile range. *A total of 43 patients underwent sleeve lobectomy. $\dagger \mathrm{A}$ total of 255 patients underwent lymph node sampling, 188 patients underwent lymph node dissection, and data were not available in 1 patient. $\ddagger$ Data were not available in 6 patients.

node-positive disease $(\mathrm{n}=98)$ was high grade in 38 of 101 patients ( $38 \%$ ), intermediate grade in 23 of 68 patients (34\%), and low grade in 37 of 341 patients $(11 \%)$.

Only $12 \%(61 / 504)$ of patients received chemotherapy or radiotherapy. Of these 61 patients, 13 had typical carcinoids, 13 had atypical carcinoids, and 35 had large-cell neuroendocrine carcinomas. Induction therapy was completed in $3 \%$ of cases (13/510) (chemotherapy in 7 cases, radiotherapy in 3 cases, and both chemotherapy and radiotherapy in 3 cases), adjuvant therapy in $9 \%$ of cases (43/504) (chemotherapy in 33 cases, radiotherapy in 5 cases, and both chemotherapy and radiotherapy in 5 cases), and both induction and adjuvant treatments in $1 \%$ of cases (5/510).

The follow-up was completed in 490 of 510 patients, with a median follow-up of 51 months (interquartile range, 18-99). Death occurred in 83 patients, and diseasespecific mortality was seen in 51 cases. Only 2 patients died within 90 days after surgery: One patient died 24 days after surgery because of an empyema and bronchopleural fistula, and 1 patient died 70 days after surgery because of a car accident. Data on recurrence 
TABLE 3. Factors influencing disease-specific survival: Univariable and multivariable analyses

\begin{tabular}{|c|c|c|c|c|}
\hline \multirow[b]{2}{*}{ Factors } & \multicolumn{2}{|c|}{$\begin{array}{c}\text { Univariable analysis } \\
\end{array}$} & \multicolumn{2}{|c|}{ Multivariable analysis } \\
\hline & $P$ value & HR $(95 \%$ CI $)$ & $P$ value & HR $(95 \%$ CI $)$ \\
\hline Age (continuous) & .001 & $1.04(1.01-1.06)$ & - & - \\
\hline Gender (female vs male) & .001 & $2.61(1.49-4.58)$ & - & - \\
\hline Smoking history (never vs current/former) & $<.001$ & $5.46(2.45-12.1)$ & - & - \\
\hline $\begin{array}{l}\text { ECOG performance status (reference } 0 \text { ) } \\
\quad 1 \\
\quad \geq 2\end{array}$ & $\begin{array}{l}.29 \\
.11 \\
.91\end{array}$ & $\begin{array}{l}1.71(0.88-3.31) \\
1.09(0.26-4.53)\end{array}$ & - & - \\
\hline Previous malignancy (no vs yes) & .52 & $0.80(0.40-1.59)$ & - & - \\
\hline Symptoms (no vs yes) & .54 & $0.84(0.48-1.47)$ & - & - \\
\hline Extent of resection (extended vs limited) & .12 & $1.90(0.85-4.21)$ & - & - \\
\hline $\begin{array}{l}\text { Lymphadenectomy (reference none) } \\
\text { Lymph node sampling } \\
\text { Lymph node dissection }\end{array}$ & $\begin{array}{l}.08 \\
.09 \\
.26\end{array}$ & $\begin{array}{l}1.75(0.02-1.31) \\
1.40(0.78-2.52)\end{array}$ & - & - \\
\hline $\begin{array}{l}\text { Histology (reference G1) } \\
\text { G2 } \\
\text { G3 }\end{array}$ & $\begin{array}{l}<.001 \\
<.001 \\
<.001\end{array}$ & $\begin{array}{l}5.95(2.35-15.0) \\
20.6(9.79-43.1)\end{array}$ & $\begin{array}{r}<.001 \\
.001 \\
<.001\end{array}$ & $\begin{array}{l}4.89(1.88-12.7) \\
17.8(7.81-37.7)\end{array}$ \\
\hline $\begin{array}{l}\text { pT (reference pT1) } \\
\text { pT2 } \\
\text { pT3 } \\
\text { pT4 }\end{array}$ & $\begin{array}{r}<.001 \\
.001 \\
<.001 \\
<.001\end{array}$ & $\begin{array}{l}2.91(1.51-5.59) \\
4.83(2.23-10.5) \\
12.2(4.50-32.8)\end{array}$ & $\begin{array}{l}.005 \\
.02 \\
.35 \\
<.001\end{array}$ & $\begin{array}{l}1.49(0.76-2.93) \\
1.50(0.64-3.47) \\
6.52(2.33-18.3)\end{array}$ \\
\hline Tumor location (central vs peripheral) & .16 & $1.58(0.83-2.97)$ & - & - \\
\hline $\mathrm{pN}$ (reference pN0) & .001 & & .34 & \\
\hline N1 & .001 & $2.84(1.49-5.41)$ & .68 & $1.16(0.58-2.30)$ \\
\hline $\mathrm{N} 2$ & .02 & $2.94(1.23-7.03)$ & .14 & $2.01(0.79-5.09)$ \\
\hline
\end{tabular}

$H R$, Hazard ratio; $C I$, confidence interval; $E C O G$, Eastern Cooperative Oncology Group; $G 1$, typical carcinoid; $G 2$, atypical carcinoid; $G 3$, large-cell neuroendocrine carcinoma

were available in 484 of 510 patients. The disease recurred in 83 of 48 cases. The recurrence was local (along the surgical margins or in the residual lobe after sublobar resection) in 12 patients $(2 \%)$, regional in 21 patients $(4 \%)$ (14 in the mediastinal lymph nodes and 7 in the ipsilateral lung), and systemic in 50 patients (10\%) (18 in the liver, 9 in the brain, 7 in the bones, 4 in the contralateral lung, 3 in the adrenal glands, 4 in $>1$ site and 5 in a nonspecified tissue).

On univariable analysis, the factors influencing disease-specific survival were age, gender, smoking history, histologic subtype, pT, and $\mathrm{pN}$ (Table 3). In the multivariable analysis, age, gender, and smoking history were not independently associated with disease-specific survival when adjusted for histologic subtype, $\mathrm{pT}$, and $\mathrm{pN}$. Only histologic subtype and pT remained independently associated with disease-specific survival at the final multivariable analysis (Table 3 ). When patients with node-positive disease were excluded and the same regression analysis was performed with N0 patients, histologic subtype (hazard ratio, 2.16; confidence interval [CI], 1.34-3.50; and $P=.002$ ) and pT (hazard ratio, 1.52; CI, 1.20-1.93; and $P=.001$ ) were the only factors independently associated with disease-specific survival.
Five-year disease-specific survival and recurrence rates were calculated by pT under each histologic subtype and are shown in Table 4. New stage groupings were then created by incorporating $\mathrm{pT}$ with similar survival and recurrences resulting in the proposed staging system: IA (pT1-2 G1), IB (pT3 G1, pT1 G2), IIA (pT4 G1, pT2-3 G2, pT1 G3), IIB (pT4 G2, pT2-3 G3), and III (pT4 G3).

Five-year disease-specific survivals using this proposed NETL-specific staging system were $97.9 \%(95 \% \mathrm{CI}$, 94.3-99.2), 81.0\% (95\% CI, 53.7-93.1), 69.1\% (95\% CI, 51.4-81.5), $51.8 \% \quad(95 \%$ CI, 34.5-66.7), and $0 \%$ $(P<.001)$ for stage IA, IB, IIA, IIB, and III, respectively (Figure 1). After analyzing the influence of this NETL-specific staging system on disease-specific survival in the subgroup of N0 patients only, we observed the same capability of stratifying survival with only a lower differentiation between stage IA and IB. In this N0 group, the 5-year disease-specific survivals were $97.6 \%(95 \%$ CI, 95.0-100.0) (death $\mathrm{n}=7$ ), 96.2\% (95\% CI, 88.8-100) (death $\mathrm{n}=2), \quad 70.4 \% \quad(95 \% \quad \mathrm{CI}, 53.7-87.1)$ (death $\mathrm{n}=11), 53.7 \%(95 \%$ CI, 31.1-76.4) (death $\mathrm{n}=10)$, and $0 \%($ death $\mathrm{n}=2)(P<.001)$ for stage IA $(\mathrm{n}=276)$, IB $(\mathrm{n}=43)$, IIA $(\mathrm{n}=43)$, IIB $(11=32)$, and III $(\mathrm{n}=3)$, respectively. 
TABLE 4. Five-year disease-specific survival and recurrence rate stratified by $\mathrm{pT}$ and histologic subtype

\begin{tabular}{|c|c|c|c|c|c|c|c|c|c|c|c|c|}
\hline & \multicolumn{4}{|c|}{ G1-typical carcinoids } & \multicolumn{4}{|c|}{ G2-atypical carcinoids } & \multicolumn{4}{|c|}{ G3-large-cell NETL } \\
\hline & $\begin{array}{c}\text { Patients } \\
\text { n }\end{array}$ & $\begin{array}{c}\text { Death } \\
\text { n }\end{array}$ & $\begin{array}{c}\text { 5-y DS } \\
\%\end{array}$ & $\begin{array}{c}\text { Recurrence } \\
\text { n (\%) }\end{array}$ & $\begin{array}{c}\text { Patients } \\
\text { n }\end{array}$ & $\begin{array}{c}\text { Death } \\
\text { n }\end{array}$ & $\begin{array}{c}\text { 5-y DS } \\
\%\end{array}$ & $\begin{array}{c}\text { Recurrence } \\
\text { n }(\%)\end{array}$ & $\begin{array}{c}\text { Patients } \\
\text { n }\end{array}$ & $\begin{array}{c}\text { Death } \\
\text { n }\end{array}$ & $\begin{array}{c}\text { 5-y DS } \\
\%\end{array}$ & $\begin{array}{c}\text { Recurrence } \\
\text { n }(\%)\end{array}$ \\
\hline pT1 & 255 & 6 & 97.3 & $14(6)$ & 37 & 4 & $62.9^{*}$ & $5(14)$ & 35 & 8 & 62.9 & $12(38)$ \\
\hline pT2 & 64 & 1 & 100.0 & $5(8)$ & 21 & 5 & 54.9 & $8(40)$ & 35 & 12 & 54.9 & $14(44)$ \\
\hline pT3 & 19 & 1 & 90.9 & $5(26)$ & 9 & - & 100.0 & $3(33)$ & 25 & 9 & 42.0 & $12(60)$ \\
\hline pT4 & 3 & 1 & 66.7 & $2(67)$ & 1 & - & 100.0 & $1(100)$ & 6 & 4 & 0.0 & $2(67)$ \\
\hline
\end{tabular}

G1, Typical carcinoid; G2, atypical carcinoid; G3, large-cell neuroendocrine carcinoma; $N E T L$, neuroendocrine tumors of the lung; $D S$, disease-specific survival. *Five-year disease-specific survivals were $92.3 \%$ and $53.3 \%$ for pT1a and pT1b disease, respectively.

Comparatively, using the 7 th edition TNM lung cancer staging system, 5-year disease-specific survivals for the whole cohort were $95.0 \%$ (95\% CI, 90.5-97.5), 92.3\% (95\% CI, 80.6-97.1), 67.7\% (95\% CI, 49.8-80.4), 70.9\% (95\% CI, 46.3-85.7), and 65.1\% (95\% CI, 44.6-79.5) for stage IA, IB, IIA, IIB, and III, respectively (Figure 2).

Cox proportional hazard models, stratified by treatment center, were fit for both the proposed NETL-specific staging system and the 7th edition TNM. The NETL-specific staging system classification had a better model fit as indicated by the lower value for $-2 * \log$-likelihood (NETL-specific staging system $=473.8 ; 7$ th edition TNM staging system $=534.0$ ). Hazard ratios with $95 \%$ confidence limits are presented for the comparison of stage IA with IB, IIA, IIB, and III in Table 5.

\section{DISCUSSION}

In this international, multi-institutional analysis of patients with NETL undergoing curative resection, we have identified 2 main factors associated with diseasespecific survival: the pathologic tumor grouping (pT) and the histology of the tumor. These 2 factors were then used to redefine the staging group definitions in the current AJCC 7th edition TNM lung cancer staging system to create a staging system specific to neuroendocrine tumors. In comparison with the AJCC 7th edition survival curves, the proposed NETL staging system provides better discrimination between the staging groups (I-III) and between the staging subgroups (eg, IA vs IB) for disease-specific survival (Video 1).

The inclusion of histology and the regrouping of pT along with disease-specific mortality in the NETL staging system seem to overcome the limitations of 7th edition TNM staging system that used overall survival, failed to distinguish between low and intermediate grade, did not include large-cell neuroendocrine tumors, and maintained the same tumor size groupings used for NSCLC. ${ }^{2}$ Although this classification was able to stratify survival among staging classes (eg, I vs II vs III vs IV), it was not able to stratify survival among staging subclasses (eg, IA vs IB or IIA vs IIB). This is likely for several reasons. First, tumor size alone is not as significant a variable in neuroendocrine tumors, which means larger tumors can be grouped together particularly for low-grade tumors. Second, the added T-stage descriptors remain important once the tumor reaches a certain size, involves the pleura, or is close to the carina. The biology of tumors based on the subgroup histology has a significant impact on stage separation.

The limitations of using the AJCC 7th edition, TNM staging for neuroendocrine tumors is further exposed by the European Society Thoracic Surgery (ESTS) Neuroendocrine Tumor Working Group Prognostic Model for typical carcinoids. ${ }^{7}$ This model identified 6 factors that could be used to predict survival within a large group of patients with only low-grade or typical carcinoid undergoing resection. It allowed a homogenous survival curve in 1101 patients to be redefined into 4 distinct classes with different survival, suggesting that it is necessary to rethink including neuroendocrine tumors in the current AJCC staging system. When our carcinoid study group validated the ESTS prognostic model with the low-grade tumors using this same cohort, it demonstrated clear differences between using the current TNM staging system compared with using the ESTS prognostic model to predict survival after resection. ${ }^{8}$ Furthermore, recent articles on neuroendocrine tumors still prefer to provide survival data by histology rather than TNM staging. . $^{-11}$

The need to incorporate histology into the NETL staging system seems obvious to those caring for patients with neuroendocrine tumors. It is widely recognized that survival is dramatically different between the four NETL subtypes. ${ }^{9-11}$ Low-grade (G1) neuroendocrine tumors are indolent with a low rate of lymph node and distant metastasis at presentation (5\%-15\% and 3\%, respectively) and a 5-year overall survival greater than $90 \% .^{9,10,12}$ Comparatively, intermediate-grade (G2) neuroendocrine tumors have a higher rate of lymphatic and distant metastasis at diagnosis (40\%-50\% and 20\%, respectively) and a lower 5 -year overall survival of $40 \%$ to $50 \%{ }^{9,10,12}$ Finally, large-cell neuroendocrine carcinoma and small-cell neuroendocrine carcinoma are highly aggressive (G3) with a 5-year overall survival respectively of $15 \%$ to $25 \%$ and less than $15 \% .^{10,13}$ 


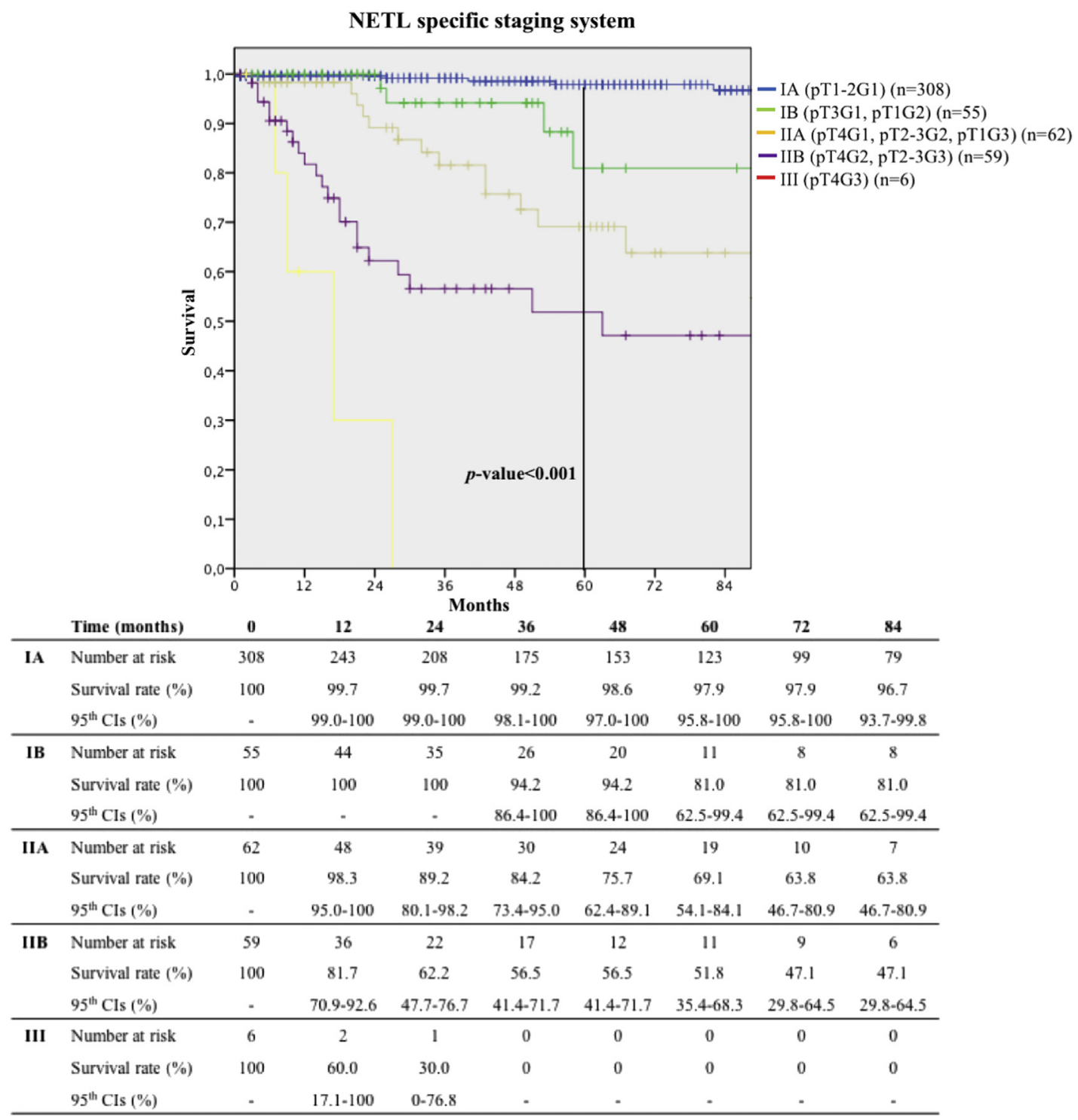

FIGURE 1. Kaplan-Meier disease-specific survival curves according to the proposed NETL-specific staging system. CI, Confidence interval; $N E T L$, neuroendocrine tumors of the lung.

Although there is consensus regarding the impact of NETL histologic subtypes on survival, the role of other factors such as tumor size or lymph node involvement is still a matter of debate. Prior studies have identified a wide variety of prognostic factors of survival in NETL including age, gender, $\mathrm{pT}, \mathrm{pN}$, and $\mathrm{pStage}$. It is likely these differences are due to not only the rarity of these tumors but also the limited number of recurrences and deaths found with these neoplasms. ${ }^{14-28}$ Pathologic $\mathrm{T}$ stage has been identified in several other studies as a key prognostic factor in determining disease-specific survival. We believe the key to understanding the influence of tumor size and its associated descriptors is also demonstrated by the increasing disease recurrence rates from $\mathrm{pT} 1$ to $\mathrm{pT} 4$ within each histological subtype. Furthermore, its influence is confirmed as an important and independent prognostic factor in the subgroup analysis of patients without lymph nodal involvement (N0).

We were surprised that the presence of lymph node metastasis was not identified as a factor associated with disease-specific survival in our series. There are several hypotheses that might explain this finding. First, this could be related to the limited number of patients with lymph nodal involvement. Second, we observed that NETL are more likely to develop distant metastases than regional metastases to hilar-mediastinal lymph nodes, which has also been demonstrated in other articles. ${ }^{14,18,24-29}$ Third, this may suggest a NETL tropism to metastasize via the 


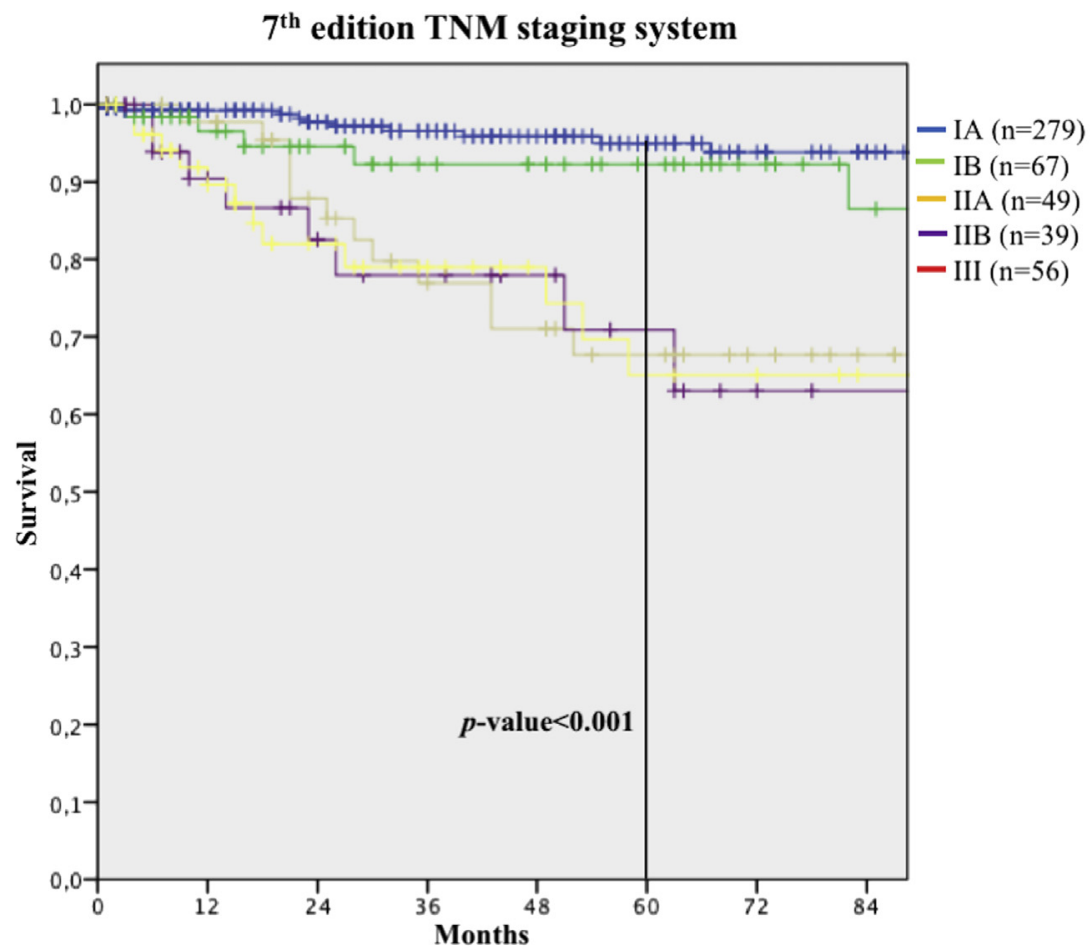

\begin{tabular}{llcccccccc} 
& Time (months) & $\mathbf{0}$ & $\mathbf{1 2}$ & $\mathbf{2 4}$ & $\mathbf{3 6}$ & $\mathbf{4 8}$ & $\mathbf{6 0}$ & $\mathbf{7 2}$ & $\mathbf{8 4}$ \\
\hline IA & Number at risk & 279 & 214 & 182 & 149 & 123 & 94 & 74 & 62 \\
& Survival rate (\%) & 100 & 99.3 & 97.8 & 96.6 & 95.9 & 95.0 & 93.9 & 93.9 \\
& $95^{\text {th }}$ CIs (\%) & - & $98.2-100$ & $95.8-99.7$ & $94.1-99.1$ & $93.1-98.7$ & $91.8-98.3$ & $90.0-97.8$ & $90.0-97.8$ \\
\hline \multirow{2}{*}{ IB } & Number at risk & 67 & 52 & 43 & 36 & 33 & 28 & 21 & 15 \\
& Survival rate (\%) & 100 & 96.6 & 94.6 & 92.3 & 92.3 & 92.3 & 92.3 & 86.5 \\
& 95 $5^{\text {th }}$ CIs (\%) & - & $91.8-100$ & $88.7-100$ & $85.0-99.6$ & $85.0-99.6$ & $85.0-99.6$ & $85.0-99.6$ & $73.6-99.5$ \\
\hline \multirow{2}{*}{ IIA } & Number at risk & 49 & 44 & 34 & 26 & 24 & 19 & 13 & 10 \\
& Survival rate (\%) & 100 & 97.8 & 87.9 & 79.8 & 71.1 & 67.7 & 67.7 & 67.7 \\
& $95^{\text {th }}$ CIs (\%) & - & $93.5-100$ & $78.0-97.9$ & $67.3-92.4$ & $56.5-85.6$ & $52.3-83.0$ & $52.3-83.0$ & $52.3-83.0$ \\
\hline \multirow{2}{*}{ IIB } & Number at risk & 39 & 24 & 18 & 16 & 12 & 9 & 4 & 3 \\
& Survival rate (\%) & 100 & 90.5 & 82.6 & 78.0 & 78.0 & 70.9 & 63.0 & 63.0 \\
& $95^{\text {th }}$ CIs (\%) & - & $80.2-100$ & $68.5-96.6$ & $62.1-93.9$ & $62.1-93.9$ & $51.3-90.5$ & $40.3-85.7$ & $40.3-85.7$ \\
\hline III & Number at risk & 56 & 39 & 28 & 21 & 17 & 14 & 12 & 10 \\
& Survival rate (\%) & 100 & 89.7 & 82.0 & 79.0 & 79.0 & 65.1 & 65.1 & 65.1 \\
& $95^{\text {th }}$ CIs (\%) & - & $81.1-98.3$ & $70.6-93.5$ & $66.5-91.5$ & $66.5-91.5$ & $47.4-82.7$ & $47.4-82.7$ & $47.4-82.7$ \\
\hline
\end{tabular}

FIGURE 2. Kaplan-Meier disease-specific survival curves according to the 7th edition TNM staging system. $C I$, Confidence interval.

blood than the lymphatic system, explaining why the lymph node involvement is not related to disease-specific survival in our cohort. Last, it is possible that the presence of a positive lymph node matters but that tumor histology is more important to survival despite the presence of nodal metastases given the distribution of node-positive disease.

In clinical practice, the 7th edition TNM classification, with its inability to stratify survival between the staging subclasses, has limited utility. ${ }^{2}$ Whereas, a diseasespecific staging system such as the one proposed may have a greater clinical impact. For example, it may allow for surveillance imaging that is based on stage such that patients with stage I tumors undergo less frequent surveillance compared with patients with higher stage tumors. In addition, knowledge of survival and recurrence risk may help guide future trials of adjuvant therapy particularly for patients with a pT4 typical carcinoid or pT2-3 atypical carcinoid (stage IIB according to the NETL-specific staging system) who may benefit from adjuvant therapy. 
TABLE 5. Cox proportional hazards models results comparing disease-specific survival between stages, using stage IA as reference

\begin{tabular}{lcccc}
\hline & \multicolumn{2}{c}{ NETL-specific staging system } & & \multicolumn{2}{c}{ 7th edition TNM staging system } \\
\cline { 2 - 4 } Stage & $\boldsymbol{P}$ value & HR $\mathbf{( 9 5} \% \mathbf{C I})$ & & HR (95\% CI) \\
\hline IB & .01 & $4.8(1.50-15.26)$ & .12 & $2.16(0.81-5.77)$ \\
IIA & $<.001$ & $10.72(4.19-27.42)$ & $<.001$ & $4.70(2.08-10.61)$ \\
IIB & $<.001$ & $25.75(10.64-62.32)$ & $<.001$ & $6.52(2.64-16.13)$ \\
III & $<.001$ & $128.49(31.98-516.25)$ & $<.001$ & $6.46(2.93-14.23)$ \\
\hline
\end{tabular}

NETL, Neuroendocrine tumors of the lung; $H R$, hazard ratio; $C I$, confidence interval.

\section{Study Limitations}

First, it is a retrospective study involving multiple centers with different practice patterns. However, the variability across center types (academic and nonacademic) and nations increases the generalizability of our results. Second, a centralized reviewed process for pathology was not available; however, by limiting the start of the data collection to 2000, we are more certain that consistent histologic interpretation was provided because standard grading criteria to distinguish among typical, atypical, and large-cell neuroendocrine carcinoma were used as of this year. ${ }^{30}$ Furthermore, the variability in pathologic assessment again speaks to pragmatic and generalizable aspects of this study to patient care and outcomes in the community-at-large (as opposed to a clinical trial with potentially less generalizability). The "noise" introduced by variable pathologic interpretation is conservative at best (ie, blunting survival differences). Third, even in this large series, the number of deaths for disease was limited, suggesting that results could be driven in completely different ways by few events. However, we opted for proposing a new NETL-specific stage system on the analysis of factors that influence the disease-specific and not the overall survival to exclude elements such as age and comorbidity that are known to impact nontumor-related deaths. Fourth, those with small-cell

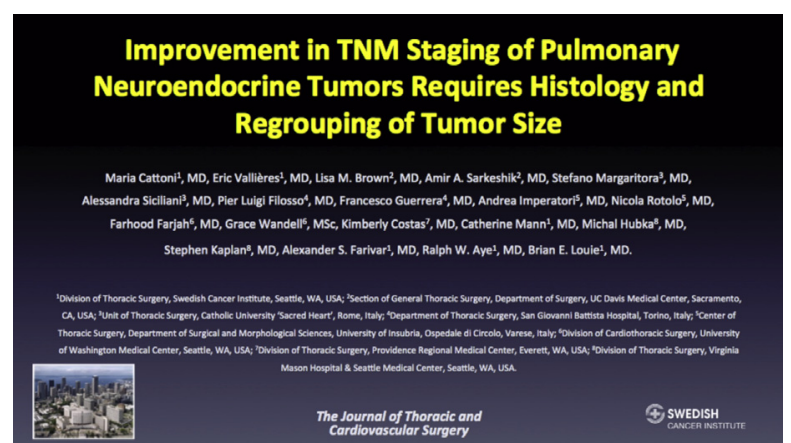

VIDEO 1. This video summarizes this study, explaining the current knowledge about pulmonary neuroendocrine tumor staging, the aim of this study, how we developed it, and its results and conclusions. Video available at: http://www.jtcvsonline.org/article/S0022-5223(17)31868-8/ fulltext. neuroendocrine tumors and those with stage IV were not included in this series, and those with high-grade neuroendocrine carcinoma (both large-cell and small-cell) were not included in the original study to apply the AJCC 7 th edition, and those with stage IV were few. ${ }^{2}$ Nevertheless, this study could be a starting point to create a more complete NETL staging system, including both small-cell neuroendocrine tumors and metastatic disease. Last, this proposed specific NETL staging system needs an external validation in an independent cohort before implementing its use in routine clinical practice.

\section{CONCLUSIONS}

NETL with their peculiar characteristics are a separate entity from NSCLC and require a disease-specific staging system. When staged using the 7th edition TNM classification for non-small cell lung cancer, the resultant survival curves often overlap and fail to distinguish survival across different stages. We propose an NETL-specific staging system that incorporates the independent prognostic factors of histologic subtype and pT. This new classification seems to stratify disease-specific survival better than the 7th edition TNM staging system and may serve as a starting point for further analyses focused on its validation and expansion to include small-cell lung cancer and metastatic disease.

\section{Conflict of Interest Statement}

Authors have nothing to disclose with regard to commercial support.

The authors thank Sandra Blitz for statistical input and advice.

\section{References}

1. Yao JC, Hassan M, Phan A, Dagohoy C, Leary C, Mares JE, et al. One hundred years after "carcinoid": epidemiology of and prognostic factors for neuroendocrine tumors in 35,825 cases in the United States. J Clin Oncol. 2008;26:3063-72.

2. Travis WD, Giroux DJ, Chansky K, Crowley J, Asamura H, Brambilla E, et al. The IASLC Lung Cancer Staging Project: proposals for the inclusion of broncho-pulmonary carcinoid tumors in the forthcoming (seventh) edition of the TNM Classification for Lung Cancer. J Thorac Oncol. 2008;3:1213-23.

3. Travis WD, Brambilla E, Burke AP, Marx A, Nicholson AG. WHO Classification of Tumours of the Lung, Pleura, Thymus and Heart. Lyon: International Agency for Research on Cancer; 2015.

4. Volante M, Gatti G, Papotti M. Classification of lung neuroendocrine tumors: lights and shadows. Endocrine. 2015;50:315-9. 
5. Detterbeck FC. Management of carcinoid tumors. Ann Thorac Surg. 2010;89: 998-1005.

6. Vittinghoff E, McCulloch CE. Relaxing the rule of ten events per variable in logistic and Cox regression. Am J Epidemiol. 2007;165:710-8.

7. Filosso PL, Guerrera F, Evangelista A, Welter S, Thomas P, Casado PM, et al. Prognostic model of survival for typical bronchial carcinoid tumours: analysis of 1109 patients on behalf of the European Association of Thoracic Surgeons (ESTS) Neuroendocrine Tumours Working Group. Eur J Cardiothorac Surg. 2015;48:441-7.

8. Cattoni M, Vallières E, Brown LM, Sarkeshik AA, Margaritora S, Siciliani A, et al. External validation of a prognostic model of survival for resected typical bronchial carcinoids. Ann Thorac Surg. August 16, 2017 [Epub ahead of print].

9. Skuladottir H, Hirsch FR, Hansen HH, Olsen JH. Pulmonary neuroendocrine tumors: incidence and prognosis of histological subtypes. A population-based study in Denmark. Lung Cancer. 2002;37:127-35.

10. Marquez-Medina D, Popat S. Systemic therapy for pulmonary carcinoids. Lung Cancer. 2015;90:139-47.

11. García-Yuste M, Matilla JM, Alvarez-Gago T, Duque JL, Heras F, Cerezal LJ, et al. Prognostic factors in neuroendocrine lung tumors: a Spanish Multicenter Study. Spanish Multicenter Study of Neuroendocrine Tumors of the Lung of the Spanish Society of Pneumonology and Thoracic Surgery (EMETNE-SEPAR). Ann Thorac Surg. 2000;70:258-63.

12. Noel-Savina E, Descourt R. Focus on treatment of lung carcinoid tumor. Onco Targets Ther. 2013;6:1533-7.

13. Fasano M, Della Corte CM, Papaccio F, Ciardiello F, Morgillo F. Pulmonary large-cell neuroendocrine carcinoma: from epidemiology to therapy. J Thorac Oncol. 2015;10:1133-41.

14. Cañizares MA, Matilla JM, Cueto A, Algar J, Muguruza I, Moreno-Mata N, et al. Atypical carcinoid tumours of the lung: prognostic factors and patterns of recurrence. Thorax. 2014;69:648-53.

15. Cardillo G, Sera F, Di Martino M, Graziano P, Giunti R, Carbone L, et al. Bronchial carcinoid tumors: nodal status and long-term survival after resection. Ann Thorac Surg. 2004;77:1781-5.

16. Cao C, Yan TD, Kennedy C, Hendel N, Bannon PG, McCaughan BC. Bronchopulmonary carcinoid tumors: long-term outcomes after resection. Ann Thorac Surg. 2011;91:339-43.

17. Filosso PL, Ruffini E, Di Gangi S, Guerrera F, Bora G, Ciccone G, et al. Prognostic factors in neuroendocrine tumours of the lung: a single-centre experience. Eur J Cardiothorac Surg. 2014;45:521-6.

18. Maurizi G, Ibrahim M, Andreetti C, D’Andrilli A, Ciccone AM, Pomes LM, et al. Long-term results after resection of bronchial carcinoid tumour: evaluation of survival and prognostic factors. Interact Cardiovasc Thorac Surg. 2014;19: 239-44.
19. Roesel C, Terjung S, Weinreich G, Gauler T, Theegarten D, Stamatis G, et al. A single-institution analysis of the surgical management of pulmonary large cell neuroendocrine carcinomas. Ann Thorac Surg. 2016;101:1909-14.

20. Herde RF, Kokeny KE, Reddy CB, Akerley WL, Hu N, Boltax JP, et al. Primary pulmonary carcinoid tumor: a long-term single institution experience. Am J Clin Oncol. August 11, 2015 [Epub ahead of print].

21. Zhong CX, Yao F, Zhao H, Shi JX, Fan LM. Long-term outcomes of surgical treatment for pulmonary carcinoid tumors: 20 years' experience with 131 patients. Chin Med J. 2012;125:3022-6.

22. Machuca TN, Cardoso PF, Camargo SM, Signori L, Andrade CF, Moreira AL, et al. Surgical treatment of bronchial carcinoid tumors: a single-center experience. Lung Cancer. 2010;70:158-62.

23. Fournel L, Falcoz PE, Alifano M, Charpentier MC, Boudaya MS, Magdeleinat P, et al. Surgical management of pulmonary large cell neuroendocrine carcinomas: a 10-year experience. Eur J Cardiothorac Surg. 2013;43:111-4.

24. Eichhorn F, Dienemann H, Muley T, Warth A, Hoffmann H. Predictors of survival after operation among patients with large cell neuroendocrine carcinoma of the lung. Ann Thorac Surg. 2015;99:983-9.

25. Veronesi G, Morandi U, Alloisio M, Terzi A, Cardillo G, Filosso P, et al. Large cell neuroendocrine carcinoma of the lung: a retrospective analysis of 144 surgical cases. Lung Cancer. 2006;53:111-5.

26. Filosso PL, Rena O, Guerrera F, Moreno Casado P, Sagan D, Raveglia F, et al Clinical management of atypical carcinoid and large-cell neuroendocrine carcinoma: a multicentre study on behalf of the European Association of Thoracic Surgeons (ESTS) Neuroendocrine Tumours of the Lung Working Group. Eur J Cardiothorac Surg. 2015;48:55-64.

27. Sarkaria IS, Iyoda A, Roh MS, Sica G, Kuk D, Sima CS, et al. Neoadjuvant and adjuvant chemotherapy in resected pulmonary large cell neuroendocrine carcinomas: a single institution experience. Ann Thorac Surg. 2011;92:1180-6.

28. Asamura H, Kameya T, Matsuno Y, Noguchi M, Tada H, Ishikawa Y, et al Neuroendocrine neoplasms of the lung: a prognostic spectrum. J Clin Oncol. 2006;24:70-6.

29. Lou F, Sarkaria I, Pietanza C, Travis W, Roh MS, Sica G, et al. Recurrence of pulmonary carcinoid tumors after resection: implications for postoperative surveillance. Ann Thorac Surg. 2013;96:1156-62.

30. Travis WD, Rush W, Flieder DB, Falk R, Fleming MV, Gal AA, et al. Survival analysis of 200 pulmonary neuroendocrine tumors with clarification of criteria for atypical carcinoid and its separation from typical carcinoid. Am J Surg Pathol. 1998;22:934-44.

Key Words: neuroendocrine tumors, pulmonary carcinoid, outcomes, staging system, survival 